\title{
Quantifying the effects of climate change and water abstraction on a population of barramundi (Lates calcarifer), a diadromous estuarine finfish
}

\author{
M. Tanimoto ${ }^{\mathrm{A}}$, J. B. Robins ${ }^{\mathrm{A}, \mathrm{C}}$, M. F. O'Neill ${ }^{\mathrm{B}}$, I. A. Halliday ${ }^{\mathrm{A}}$ \\ and $A$. B. Campbell ${ }^{\mathrm{A}}$ \\ A Agri-Science Queensland, Department of Agriculture, Fisheries and Forestry, \\ Ecosciences Precinct, GPO Box 267, Brisbane, Qld 4001, Australia. \\ ${ }^{B}$ Agri-Science Queensland, Department of Agriculture, Fisheries and Forestry, \\ Maroochy Research Station, 47 Mayers Road, Nambour, Qld 4560, Australia. \\ ${ }^{\mathrm{C}}$ Corresponding author. Email: julie.robins@daff.qld.gov.au
}

\begin{abstract}
Many aquatic species are linked to environmental drivers such as temperature and salinity through processes such as spawning, recruitment and growth. Information is needed on how fished species may respond to altered environmental drivers under climate change so that adaptive management strategies can be developed. Barramundi (Lates calcarifer) is a highly prized species of the Indo-West Pacific, whose recruitment and growth is driven by river discharge. We developed a monthly age- and length-structured population model for barramundi. Monte Carlo Markov Chain simulations were used to explore the population's response to altered river discharges under modelled total licenced water abstraction and projected climate change, derived and downscaled from Global Climate Model A1FI. Mean values of exploitable biomass, annual catch, maximum sustainable yield and spawning stock size were significantly reduced under scenarios where river discharge was reduced; despite including uncertainty. These results suggest that the upstream use of water resources and climate change have potential to significantly reduce downstream barramundi stock sizes and harvests and may undermine the inherent resilience of estuarine-dependent fisheries.
\end{abstract}

Additional keywords: fish growth, management, population model, recruitment, river discharge, Sea Bass, simulation, stock assessment.

Received 4 December 2011, accepted 21 June 2012, published online 20 A ugust 2012

\section{Introduction}

Fish stocks and fisheries will be affected by global climate change (Brander 2010; Koehn et al. 2011), with freshwater and estuarine ecosystems suggested to be among those most affected (Pittock et al. 2008). Processes that are fundamental to fish population dynamics, such as reproduction, spawning, recruitment, growth, mortality, distribution, migration, catchability, predation and competition, are expected to be affected by changes in physical and chemical environmental parameters (Ottersen et al. 2010; Gillanders et al. 2011). The environmental parameters that are expected to change include air and water temperatures, sea level, wind fields, upwelling, ocean currents, atmospheric circulation, storm frequency, rainfall, evaporation rates, salinity, ocean $\mathrm{pH}$ and UV-radiation levels (Harley et al. 2006; Poloczanska et al. 2007; Koehn et al. 2011). How these parameters change as a consequence of increased concentrations of greenhouse gases is complex, uncertain and variable. However, there is consensus that the global air temperature will increase above the $1961-1990$ average by between $0.9^{\circ} \mathrm{C}$ and
2. $6^{\circ} \mathrm{C}$ (IPCC 2007). This will have consequences for sea levels, ocean acidification and extremes of weather that will vary regionally throughout the world.

Australia's climate has already changed since the mid-20th century (Lough and Hobday 2011). Examples include warming of ocean sea-surface temperatures (Lough 2009), lowered ocean $\mathrm{pH}$ (Howard et al. 2009), strengthening and extension of the East Australian Current (Ridgway and Hill 2009) and reduced river discharges (Gräwe et al. 2010). These changes have been linked to changes in Australian fisheries. For example, changes to the western rock lobster fishery (Panulirus cygnus) are variable, depending on the frequency of El Niño events and the degree to which water temperature increases (Caputi et al. 2010). Predictions of future impacts of climate change on Australian fisheries vary among regions and species. Fishery catches may increase as a consequence of climate-driven changes to primary production in Australia's marine ecosystems (Brown et al. 2010), whereas temperate stocks of school prawns (Metapenaeus macleayi) may not be significantly affected (Ives et al. 2009). 
Table 1. River discharge to the Fitzroy River estuary

LCCDry $=$ hypothetical latent + climate change dry, LCCMed $=$ hypothetical latent + climate change median, LCCNil = hypothetical latent + no climate change, $\mathrm{LCCWet}=$ hypothetical latent + climate change wet, status quo $=$ historic mean $( \pm$ s.e. $)$ observed discharge to the estuary

\begin{tabular}{lccccr}
\hline Season & Status quo $\left(\mathrm{m}^{3} \mathrm{~s}^{-1}\right)$ & \multicolumn{3}{c}{ Percentage change mean discharge (relative to status quo) } \\
& & LCCNil & LCCWet & LCCMed & LCCDry \\
\hline Summer & $362.4( \pm 77.9)$ & -12 & +37 & -18 & -39 \\
Autumn & $227.3( \pm 44.1)$ & -3 & +28 & -13 & -42 \\
Winter & $42.3( \pm 12.1)$ & -12 & -15 & -51 & -76 \\
Spring & $26.7( \pm 9.1)$ & -29 & -44 & -55 & -82 \\
\hline
\end{tabular}

In south-eastern Australia, altered water temperatures will be a key driver of change, whereas in northern Australia, altered rainfall and river discharges will be an important driver of change (Hobday et al. 2008).

Barramundi (Lates calcarifer) is an economically important wild harvest, recreational and aquaculture species of the tropical Indo-West Pacific (Fishbase 2009). Investigating the impacts of climate change on this species is useful because barramundi is a euryhaline, top-order carnivore that occupies an ecological niche similar to American common snook (Centropomus undecimalis) and African Nile perch (Lates niloticus) (Greenwood 1976), giving the case study widespread significance. Early predictions of the impacts of climate change can inform vulnerability assessments and in combination with socioeconomic information, can be used to develop adaptive management strategies (Koehn et al. 2011; Plagányi et al. 2011).

In the current study, we developed a regional population model for barramundi that incorporated variable recruitment and growth that was a function of observed river discharge. Then, we investigated the response of the modelled population to river-discharge sequences that were modified to reflect (1) total abstraction of all licenced water and (2) projected regional climate change derived from downscaled outputs of Global Climate Model A1FI, as suggested by Clark et al. (2003) and Keyl and Wolff (2008). In addition, river discharge has not been previously included in population models of barramundi (Grace et al. 2008). Intuitively, we would expect stock size and fishery yields to be negatively affected when discharges are reduced; however, we have no information on the significance or order-of-magnitude of these changes.

\section{Materials and methods}

\section{Study species}

Barramundi is a long-lived and fast-growing species (Dunstan 1959; Russell and Garrett 1985; Griffin 1987). It is a catadromous opportunist (Pender and Griffin 1996; Milton et al. 2008), whose catch rates are statistically significantly and positively correlated with river discharge (Robins et al. 2005; Balston 2009). Barramundi recruitment is statistically significantly and positively related to discharge (Staunton-Smith et al. 2004; Halliday et al. 2011), as are its seasonal growth rates (Robins et al. 2006). An important wild-capture fishery for barramundi occurs in the Fitzroy River region $\left(\sim 23^{\circ} 23^{\prime} \mathrm{S}, 150^{\circ} 28^{\prime} \mathrm{E}\right)$ and the population dynamics of barramundi in this region are typical of stocks in northern Australia (Dunstan 1959; Robins et al. 2005).

\section{Study area}

The Fitzroy River region is located on the boundary of the tropical and temperate convergence zones (Ford et al. 2005) and has a highly seasonal pattern in river discharge (Table 1). The region's average annual climate has become warmer and drier over the past 50 years (Cai et al. 2005). Regional median climate-change projections based on results from 23 global climate models under high-emissions scenarios for a 30 -year period centred on 2050 include a $2 \%$ increase in average annual temperature, a $7 \%$ decrease in average annual rainfall and a $7 \%$ increase in average annual potential evaporation (QCCCE 2009). These changes in climate are projected to have an impact on the discharge of the Fitzroy River, although the scale of the impact varies seasonally (Table 1). Other projected changes include a $30-\mathrm{cm}$ rise in sea level, a $10 \%$ increase in cyclone intensity and frequency and a 130-km southwards shift in cyclone tracks (QCCCE 2009).

\section{Operating model}

Modelling involved the following two stages: (1) constructing parameter posterior distributions for a monthly age- and lengthstructured population model, using Markov Chain Monte Carlo sampling (MCMC with Metropolis-Hastings algorithm) calibrated to data for the Fitzroy River region from 1945 to 2005; and (2) running likely parameter values and uncertainty in simulations through the population model (i.e. the projection stage). The 1st-stage MCMC calibration process provided a large sample of parameter values for the spawner-recruitment and discharge-recruitment relationships, and for model process uncertainty. In the 2nd stage, the model moved into a 45 -year projection phase, driven by simulated parameters (i.e. resampled from the MCMC chain) and process uncertainties to assess the impacts of different discharge sequences on the modelled population. The time series for modelling commenced in 1945 and assumed that the population was in an equilibrium unfished state because no prior catch records were available and fishing effort at this time was limited (Leigh et al. 2006). The dynamics of the population were tracked monthly by applying recruitment, growth and mortality functions (for details, see Supplementary Material, available on the web).

\section{Incorporating the effects of river discharge on recruitment}

Summer and spring river discharge affects barramundi recruitment, with high discharges resulting in relatively 
strong year classes, and low discharges resulting in relatively weak year classes (Halliday et al. 2011). In the current study, expected recruitment $\left(R_{y}\right)$ was based on the spawning stock size of the previous year $\left(\hat{R}_{y}\right.$, derived from a Beverton-Holt recruitment function, see Eqn $\mathrm{S} 1$, available as Supplementary Material on the web), adjusted by the effect of anomalies in total summer discharge (i.e. December to February) and total spring discharge (i.e. September to November), and defined as

$$
\begin{aligned}
R_{y}= & \hat{R}_{y} \exp \left[\phi_{1} \hat{c}_{1}\left(\log \text { sumflow }_{y-1}^{\text {std }}\right)\right. \\
& \left.+\phi_{2} \hat{c}_{2}\left(\log \text { sprflow } w_{y-1}^{\text {std }}\right)+\varepsilon_{y}\right],
\end{aligned}
$$

where $\phi_{1}$ and $\phi_{2}$ are logic functions (explained below), $\hat{c}_{1}$ and $\hat{c}_{2}$ are coefficients estimated in the 1 st stage (i.e. the calibration phase) by MCMC, $\log$ sumflow $w_{y-1}^{\text {std }}$ and $\log$ sprflow $w_{y-1}^{\text {std }}$ are total summer and spring discharge (natural logarithm transformed and standardised to the mean total summer discharge and mean total spring discharge, respectively) in the previous year $\left(y^{-1}\right)$, with discharge representing the observed historic discharge to the Fitzroy River estuary (see Supplementary Material for details), and $\varepsilon_{y}$ was random process error (explained below). The logic functions $\phi_{1}$ and $\phi_{2}$ determined whether seasonal discharges exceeded lower or upper seasonal thresholds. Upper thresholds for total seasonal discharge in summer and spring were $128.6 \mathrm{~m}^{3} \mathrm{~s}^{-1}$ and $0.8 \mathrm{~m}^{3} \mathrm{~s}^{-1}$, respectively, and resulted in barramundi recruitment that was 'stronger' than average. Lower thresholds for total seasonal discharge in summer and spring were $20.4 \mathrm{~m}^{3} \mathrm{~s}^{-1}$ and $0.2 \mathrm{~m}^{3} \mathrm{~s}^{-1}$, respectively, and resulted in recruitment that was 'weaker' than average. Threshold values were based on the quantitative results of Staunton-Smith et al. (2004) and Halliday et al. (2011). Recruitment was further modified to include random process error $\left(\varepsilon_{y}\right)$ to account for environmental fluctuations to recruitment that were additional to and independent of discharge. In the 2 nd stage (i.e. the projection stage) recruitment error $\left(\varepsilon_{y}\right)$ was randomly sampled every year from a log-normal distribution of $(\sim \ln (N(0,0.31)))$. An $\varepsilon_{y}$ with a standard deviation of 0.31 resulted in recruitment variation of $\sim 50 \%$ because of river discharge (Halliday et al. 2011) and 50\% because of random error. Monthly recruitment was the product of the within-fishing-year recruitment pattern $\left(\Phi_{m}\right)$ and the total annual number of barramundi recruits.

\section{Incorporating discharge effects on growth}

The growth of fish older than 12 months was determined by a discharge-dependent size-transition matrix $\left(P_{l, l^{\prime}}\right)$. The operating model applied an extended von Bertalanffy growth function developed by Robins et al. (2006), which included the effects of season and discharge. Monthly historic discharge to the estuary between 1945 and 2005 inclusive was used to calculate all possible growth increments per length class per calendar month, using discharge as an input parameter (see Eqn S10, available as Supplementary Material on the web). Possible growth increments were used to construct length-class transition matrices representing the discharge- and season-specific probabilities of an individual growing from one length class to another.
A gamma-probability density function was used to construct the length-class transition matrices, as follows:

$$
P_{l, l^{\prime}}=f(l \mid a, b)=\frac{1}{b^{a} \Gamma(a)} l^{a-1} e^{-\frac{l}{b}},
$$

where $a$ is the shape parameter and $b$ is the scale parameter, which are equivalent to $\mu_{l^{\prime}}^{2} / \sigma^{2}$ and $\sigma^{2} / \mu_{l}$, respectively (where $\mu_{l}=$ mean expected growth increment of length class $l, \sigma=$ standard deviation). The final length-class transition matrix was normalised for each length class $\left(P_{l, l^{\prime}} / \sum_{l=L_{\min }}^{L_{\max }} P_{l, l^{\prime}}\right)$.

Variability around the mean expected growth increment was assumed constant for all length classes.

\section{Calibrating the operating model}

Three parameters were estimated in the 1st stage, including virgin recruitment $\left(\hat{R}_{0}\right)$, and the coefficients for summer and spring discharge ( $\hat{c}_{1}$ and $\hat{c}_{2}$, respectively) of Eqn 1. A quasiBayesian approach was used for parameter estimation. As we knew little about the distributions of the free parameters, we used uniform (non-informative) priors for each parameter. A Monte Carlo Markov Chain (MCMC) algorithm was used to obtain the 'posteriors' from tracing the log-likelihoods for the following data: (1) standardised monthly barramundi catch rates between 1990 and 2005; (2) the observed proportion of barramundi catch-at-age between 2000 and 2005; and (3) the observed proportion of barramundi catch-at-length between 2000 and 2005 (see Supplementary Material for details).

The total objective function (TOF) for model calibration was calculated by adding normal negative log-likelihoods (Haddon 2001) for barramundi catch per unit effort $\left(L_{\text {cpue }}\right)$, catch-atlength $\left(L_{\text {length }}\right)$ and catch-at-age $\left(L_{\text {age }}\right)$, as follows:

$$
\begin{aligned}
& \text { TOF }= 2 \times-\log \left(L_{\text {cpue }}\right)+0.1 \times-\log \left(L_{\text {length }}\right)+0.1 \\
& \times-\log \left(L_{\text {age }}\right)+1 \times-\log \left(\lambda_{1}\right)+1 \times-\log \left(\lambda_{2}\right) \\
& \lambda_{1}=\left\{\begin{array}{ll}
0 & \text { if } \operatorname{catch}(m) \leq B(m) \\
\sum(\operatorname{catch}(m)-B(m))^{2} & \text { otherwise }
\end{array},\right.
\end{aligned}
$$

where $\operatorname{catch}(m)$ was the total monthly catch and $B(m)$ was the monthly exploitable biomass. A penalty function $\left(\lambda_{2}\right)$ was used (Hall and Watson 2000) to avoid the operating model tracing unrealistically large population sizes, with improbably low estimates of exploitation, and was calculated as follows:

$$
\lambda_{2}=\left\{\begin{array}{ll}
0 & \text { if } \frac{C_{y}}{R_{y}} \geq h f \\
1000\left(h f-\frac{C_{y}}{R_{y}}\right)^{2} & \text { otherwise }
\end{array},\right.
$$

where $C_{y}$ is the total annual catch (number of fish) in Year $y, R_{y}$ is recruitment adjusted by anomalies in summer and spring discharge from the previous year, $y^{-1}$; and $h f$ is the minimum harvest fraction. The value 1000 in Eqn 4 ensured adequate weighting in the MCMC process (Hall and Watson 2000). Because each log-likelihood term varied in magnitude, different weightings were imposed so that each term contributed equally and ensured that the age and length data did not compromise the 
model fit to standardised catch rate (Francis 2011). The age and length log-likelihood data were measured by a cumulative distribution function, using the proportion of fish in each catch-atage or catch-at-length category (Leigh et al. 2006).

Assessing the satisfactory convergence to the posterior distribution is a potentially major problem with the use of the MCMC algorithm (Punt et al. 2006). Therefore, assessment of satisfactory model convergence was based on (1) visual examination of traces for key model outputs, (2) comparing the posterior means of the free parameters at the start (runs 500010000 ) with those at the end of the sequence (runs 20000 40000 ) and testing for statistical difference based on the standard deviations of each (Geweke 1992), and (3) computing the Gelman-Rubin diagnostic statistic for each free parameter (Gelman et al. 2004). The results of the model calibration were based on a minimum annual harvest fraction $(h f)$ of 0.05 .

\section{Simulation of barramundi production under hypothetical discharges}

The 2nd stage of modelling (i.e. the projection stage) was designed to explore the magnitude and direction of impacts on barramundi production of (1) total abstraction of all licenced water and (2) projected regional changes to river discharge derived from downscaled outputs of the Global Climate Model A1FI. The projection stage was initialised by fish abundance estimated from the last year of the MCMC calibration of the operating model (i.e. Stage 1). For projections, alternative values of $\hat{R}_{0}$ (virgin recruitment), $\hat{c}_{1}$ (summer-discharge coefficient) and $\hat{c}_{2}$ (spring-discharge coefficient) were randomly selected 1000 times from the MCMC chain of posteriors, to allow uncertainty in the model parameters to be included in projected sequences.

\section{River-discharge scenarios}

We considered five scenarios for river discharge to the Fitzroy River estuary. The first scenario, referred to as 'status quo', was the observed historic discharge to the estuary (Robins et al. 2005), and included actual levels of upstream water abstraction (see Supplementary Material for details). Four other modified scenarios were considered. All were supplied by the Queensland Department of Environment and Resource Management, which undertakes detailed quantitative modelling of water resources for water-management purposes (for details, see Water Assessment Group 2009). The four modified scenarios all assumed total abstraction of all licenced water (including latent licences), plus the following levels of projected climate change: (1) no change (latent + nil climate change; LCCNil), (2) 10th percentile projected climate change (latent + climate change wet; LCCWet), (3) the 50th percentile of projected climate change (latent + climate change median; LCCMed) and (4) the 90th percentile of projected climate change (latent + climate change dry; LCCDry). Discharge scenarios that included climate change were based on the historical-discharge time series modified by the parameter-change percentages to rainfall and potential evaporation in the central Queensland region under Global Climate Model A1FI for the 2050 projection period (QCCCE 2009). Outputs of this climate model most closely follow current trends in emissions and assume a high reliance on fossil fuels. For projected climate change discharge secnarios, the 10th percentile case is where the flow is exceeded $10 \%$ of the time (i.e. the wetter case), while the 90th percentile case is where the flow is exceeded $90 \%$ of the time (i.e. the drier case).

\section{Generating projected hypothetical sequences}

Outputs of Global Climate Models relate to mean changes in climate parameters and do not provide a future time series that encapsulates inter- and intra-annual climate variability. Therefore, we generated hypothetical discharge sequences by randomly selecting (with replacement) 45 annual sequences of monthly discharge (i.e. 1 year - July to June) from the historic (or modified) discharge time series. This procedure was repeated 50 times to generate replicates. We applied the same random selection of annual discharge sequences across scenarios (e.g. status quo, LCCNil) for any given replicate (i.e. 'same-year selection'). This provided (1) plausible within-year variability in discharge and (2) the same level of inter-annual fluctuation in climate variability between scenarios. Therefore, the main differences between the hypothetical discharge sequences of the five scenarios considered were the level of water use and the degree of climate change. The hypothetical discharge sequences were used as input to the population model, in combination with 50 randomly selected sets of $\hat{R}_{0}, \hat{c}_{1}$ and $\hat{c}_{2}$ taken from the 1000 length chain of posteriors derived from the $\sim 40000 \mathrm{MCMC}$ calibration chain.

\section{Evaluation of changes in barramundi production}

The effects of changed discharge on barramundi were evaluated by comparing relative differences in equilibrium maximum sustainable yield (MSY) among scenarios, as well as the following indicators averaged over the last 20 years of the simulations (i.e. 2030-2050): exploitable biomass, spawning stock size (number of eggs $\times 10^{6}$ ), annual catch, mean catch-at-age and mean catch-at-length. The effect of the discharge scenario on these indicators was tested using a residual maximumlikelihood model (REML, GENSTAT 2008), with scenario as a fixed effect and replicate as a random effect. Data for all fishery indicators except mean catch-at-age and mean catch-at-length were natural-logarithm transformed before analysis to normalise residuals. Predicted means for each fishery indicator from the REML analysis were tested for significant differences among scenarios, using the criterion of means having differences greater than twice the average standard error for each term (i.e. estimated 1.s.d.).

\section{Sensitivity of the model to variation in the stock-recruitment relationship}

For most species, the relationship between spawning biomass and subsequent recruitment is poorly known (Hilborn and Stokes 2011). We recognised that the shape of the stockrecruitment curve had potential to significantly influence the outputs of the operating model and assessment of the impacts of the hypothetical discharge scenarios. Therefore, we incorporated uncertainty in the spawner-recruit relationship by tuning and projecting the model with alternate values of steepness $(h)$ of $0.5,0.7$ and 0.9 . We considered a $h$ of 0.7 to be the base case for barramundi because of (1) expert consensus (Grace et al. 


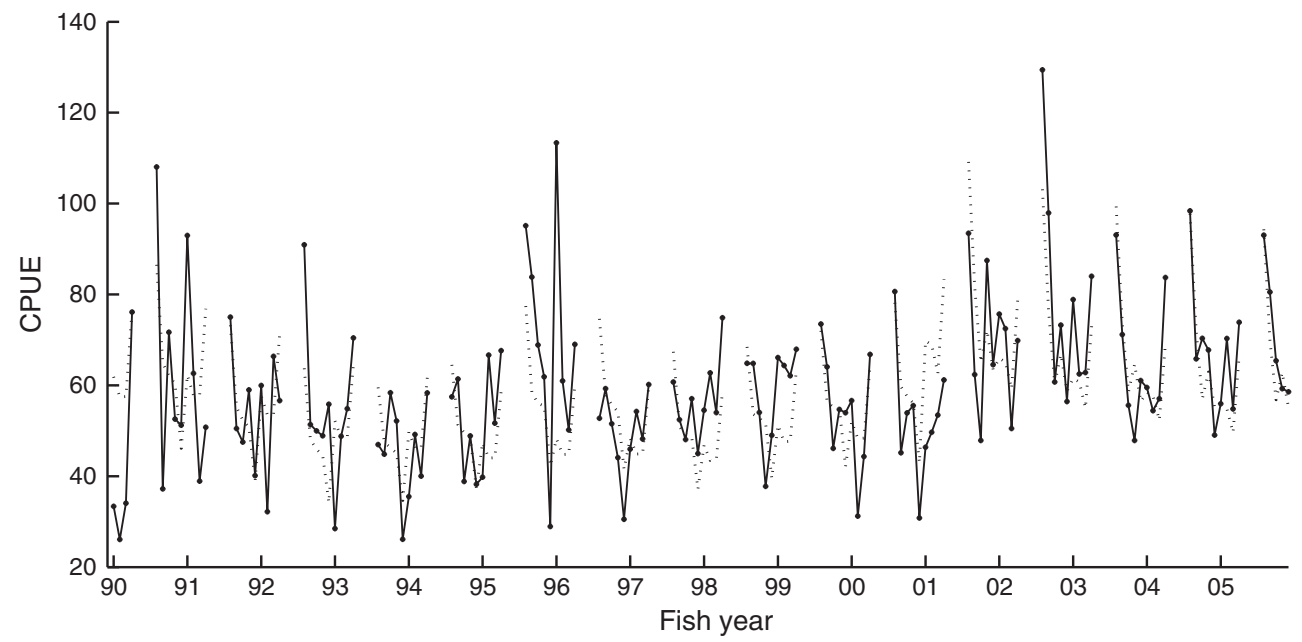

Fig. 1. Mean monthly catch per unit effort (CPUE) of barramundi in the Fitzroy River region between 1990 and 2005, showing standardised CPUE from general linear model (solid line) and fitted CPUE from the monthly age- and length-structured population model for $h=0.7$ (dotted line). Fishing year $=$ July-June. Note the annual fishery closure between November and January (inclusive).

2008) and (2) similarities to common snook (i.e. diadromous, protandrous, longevity $>20$ years, and maturity at 5-7 years), for which 0.7 is considered to be the base case (Muller and Taylor 2006).

\section{Assumptions - simplification of ecological processes}

The current work did not consider all the potential effects of climate change on barramundi population dynamics because many effects are not known or quantified (Gillanders et al. 2011). Temperature is a key or primary climate variable (Koehn et al. 2011) projected to increase under global climate change and is a 'master factor' in many ecological processes, such as activity, feeding, growth and reproduction (Kennedy 1990; Jobling 1997; Pankhurst and Munday 2011). Barramundi has a wide thermal optimum for growth and protein metabolism, i.e. $27-33^{\circ} \mathrm{C}$ (Katersky and Carter 2007), and a critical thermal maximum of $44.5^{\circ} \mathrm{C}$ (Rajaguru 2002). Therefore, it is unlikely that projected temperature increases for the Fitzroy River region in 2050 will be beyond the thermal limits of this species.

For simplicity, we assumed that the empirical relationship between discharges and seasonal growth rates of barramundi remained valid within the range of discharges considered in the current work and that prey availability was not critically limited in any hypothetical scenario. Barramundi is a non-specialised predator that exploits pulses in prey availability in fresh, estuarine or saltwater habitats. Barramundi is also cultured widely, where it feeds on a pellet diet. Therefore, we suggest that barramundi is very adaptable to available food sources, but recognise that the composition and abundance of barramundi prey may alter with long-term climate change, and that this is an area requiring further research.

Non-independent effects of forcing variables were not explicitly specified, i.e. when one factor is strengthened or weakened by variation in another and when the combined influence of two factors pushes a population beyond a critical threshold (Harley et al. 2006). Quantitative data on non-linear and non-independent effects of forcing variables were not available for the present study.

\section{Results}

Model convergence

Visual examination of the MCMC traces for estimated values of $\hat{R}_{0}, \hat{c}_{1}$ and $\hat{c}_{2}$ suggested a reasonable fit across key model outputs. Geweke statistics indicated no significant differences in the mean (and variance) of each parameter between the first and second half of the MCMC chain. Gelman statistics for all model parameters were $<1.05$. These three indicators suggested no convergence problems for any of the key model outputs.

Plots of observed versus predicted catch rates and age frequencies (Figs 1, 2) suggested that the model provided a reasonable representation of the Fitzroy River barramundi population. At this stage, we did not favour estimating more parameters or reweighting log-likelihoods to improve predicted length frequencies (Fig. 2). Estimated parameter values of virgin recruitment $\left(\hat{R}_{0}\right)$, summer-discharge recruitment coefficient $\left(\hat{c}_{1}\right)$ and spring-discharge recruitment coefficient $\left(\hat{c}_{2}\right)$ were significant $(P<0.01$; Table 2$)$.

\section{Barramundi simulation - fishery indicators}

Values for the fishery indicators were presented as percentage change compared with the status quo scenario because our aim was to explore relative change resulting from altered river discharges. Mean values for exploitable biomass, spawning stock size (SpSS), MSY, annual catch and fish length were greatest for the status quo scenario and reduced for all other scenarios, with the differences significant at $P=0.001$ (Fig. 3; $h=0.7$ base case). $F_{4,196}$ statistics were 1085 for biomass, 1481 for SpSS, 41711 for MSY, 877 for annual catch and 558 for catch-at-length. Mean values of catch-at-age were the reverse of this pattern $\left(F_{4,196}=1880, P<0.001\right)$, with the mean age of fish (caught) youngest in the status quo scenario 

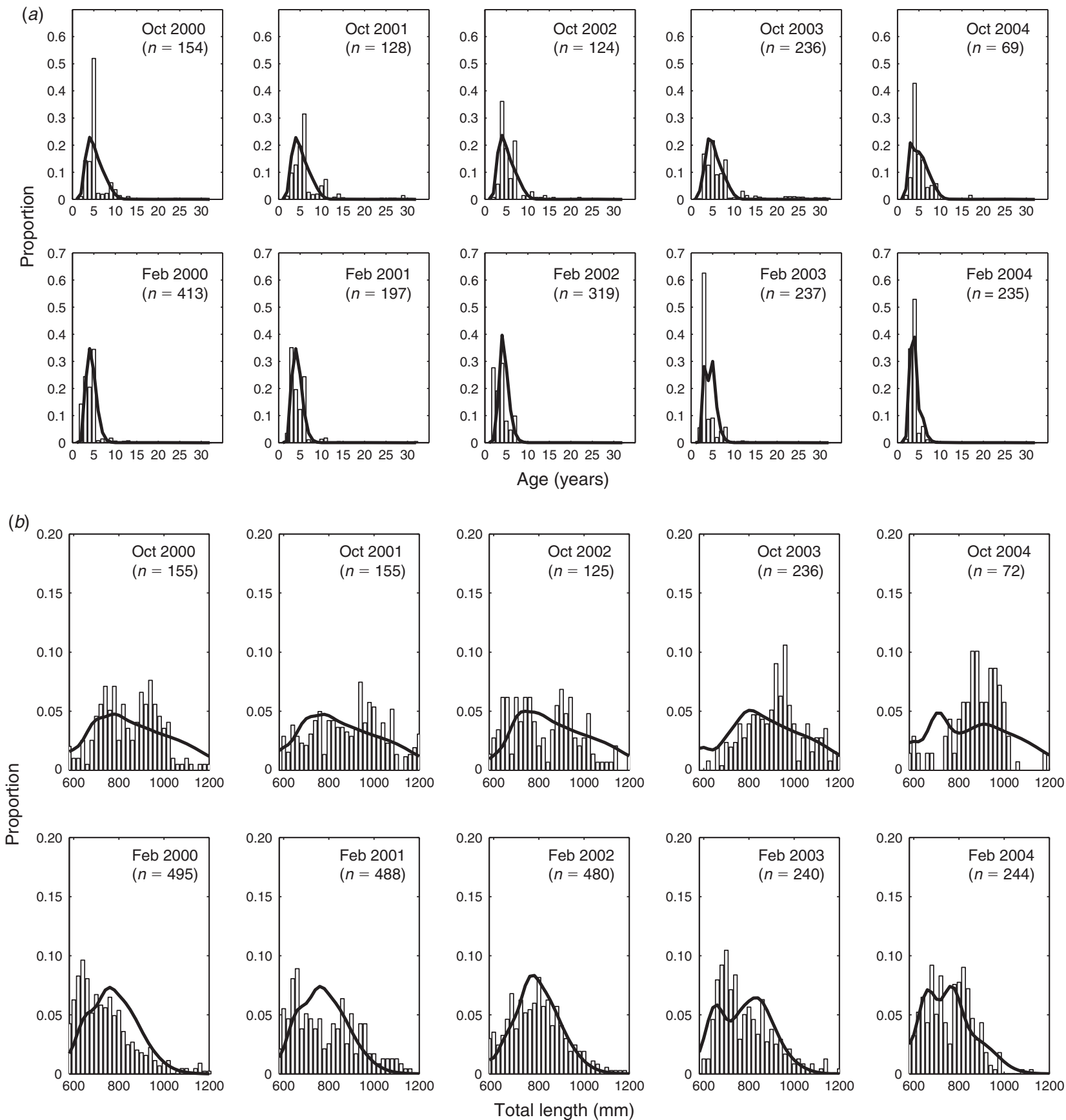

Fig. 2. Frequencies of $(a)$ catch-at-age and $(b)$ catch-at-length for barramundi in the Fitzroy River region between October 2000 and February 2005 , showing observed frequencies (data from Halliday et al. 2011) (histogram boxes) and fitted frequencies from the monthly age- and length-structured population model for $h=0.7$ (solid line).

and oldest in the LCCDry scenario. This was a consequence of fish growing more slowly under hypothetical scenarios of reduced discharge and therefore taking longer to reach minimum legal size.

Reductions in the mean exploitable biomass compared with the status quo scenario ranged from $4 \%$ for the LCCWet scenario up to $25 \%$ for the LCCDry scenario. On the basis of the results for the LCCNil scenario, $\sim 10 \%$ of the reductions in mean exploitable biomass could be attributed to the total abstraction of all licenced water. Mean spawning stock size was reduced by $5-42 \%$ (Fig. 3 ). MSY was reduced by a $4 \%$, $23 \%, 33 \%$ and $45 \%$ for the LCCWet, LCCNil, LCCMed and LCCDry scenarios, respectively. Mean annual catch was reduced by between $4 \%$ (LCCWet) and 23\% (LCCDry), with 
Table 2. Parameters estimates (median \pm s.d.) for the Beverton-Holt recruitment function modified by anomalies in summer and spring discharge (Eqn 1) for pre-specified values of recruitment-curve steepness $(h)$

Values were generated from their posterior distributions of 1000 random Markov Chain Monte Carlo samples

\begin{tabular}{lccc}
\hline$h$ & $\begin{array}{c}\text { Virgin recruitment, } \hat{R}_{0} \\
\left(\text { no. of fish } \times 10^{6}\right)\end{array}$ & $\begin{array}{c}\text { Summer-discharge } \\
\text { coefficient, } \hat{c}_{1}\end{array}$ & $\begin{array}{c}\text { Spring-discharge } \\
\text { coefficient, } \hat{c}_{2}\end{array}$ \\
\hline 0.5 & $0.6988( \pm 0.1612)$ & $0.2720( \pm 0.1247)$ & $0.0508( \pm 0.0271)$ \\
0.7 & $0.6347( \pm 0.1486)$ & $0.3221( \pm 0.1126)$ & $0.0859( \pm 0.0353)$ \\
0.9 & $0.6477( \pm 0.1503)$ & $0.2019( \pm 0.1210)$ & $0.0594( \pm 0.0300)$ \\
\hline
\end{tabular}

total abstraction of all licenced water (LCCNil) accounting for $9 \%$ of the reduction.

Values of all fishery indicators under alternate $h$ values showed similar trends in percentage change compared with the status quo scenario, although individual values differed from that of the base case (i.e. $h=0.7 ; P<0.01$ ). Greater reductions in mean values of fishery indicators occurred for the model tuned and projected for $h=0.5$, whereas lesser reductions in values of fishery indicators occurred for the model tuned and projected for $h=0.9$ (Fig. 4).

\section{Discussion}

Many approaches are needed to understand the possible impacts of climate change on fishery resources and to inform planning processes about adaptation to climate change (Plagányi et al. 2011). We explored possible population responses of a single species by coupling downscaled outputs from a Global Climate Model (GCM) to an environmentally responsive fishery population dynamics model - the first of its kind for barramundi. Simulation results were in line with our expectations; reduced discharges resulted in significantly reduced production, with one exception, namely, fishery production under the LCCWet scenario. In this scenario, mean exploitable biomass was reduced by $4 \%$, despite a $37 \%$ increase in summer river discharge. The reduction was a consequence of a $44 \%$ reduction in spring river discharge which negatively affected the growth and recruitment of the simulated barramundi population that could not be compensated for by the $37 \%$ increase in summer river discharge. The result illustrated that the projected effects of altered river discharge on fishery production are complex and that simple linear projections, such as might be based on observed river-discharge-catch relationships (e.g. Robins et al. 2005; Balston 2009) could be misleading.

\section{Analysis of validity of methods and problems encountered}

Two issues were identified when simulating climate-change impacts on fish stocks. First, large variability in regional GCM outputs (i.e. 10th to 90 th percentiles) produced large variability in simulated impacts (Fig. 3). This was particularly true in the Fitzroy River region where projected changes in annual rainfall range between $-24 \%$ and $+10 \%$ (QCCCE 2009). Modelling climate systems is complicated, but until the range of uncertainty in GCM regional outputs is refined, these outputs will be a major source of uncertainty to any simulation of the potential impacts of climate change on a fishery.

Second, the lack of predicted future time series of relevant climate parameters (in this case, river discharge) that encapsulates inter- and intra-annual climate variability limits climatechange simulation to estimating mean responses selected from an appropriately adjusted historical time series. Comparison of the same time series among replicates of each climate-change scenario (i.e. same-year selection) permitted our analyses to focus on the effects of long-term climate change rather than inter- or intra-year climate variability. This was important in detecting differences among climate-change scenarios. We also found it useful to consider the appropriate temporal grouping of the time series, because climate-dependent parameters are often dependent on those of the preceding month(s). In our case, we selected 12 sequential months (of discharge) that matched the biological year of our selected species (Staunton-Smith et al. 2004; Robins et al. 2006) and because the Australian climate (especially rainfall) is influenced at an annual scale by El NiñoLa Niño events, which are often initiated after the Australian winter (Chiew et al. 1998).

\section{Implications of projected climate change for barramundi}

Barramundi is a long-lived (up to 32 years) tropical species with high fecundity and a prolonged reproductive life-span. King and MacFarlane (2006) classified such species as long-lived (periodic) strategists, capable of persisting through poor conditions to immediately exploit good conditions, as occurs during the flood and drought climate cycles of northern Australia. Other characteristics of this species which indicate that it (and species with similar traits) may be resilient to climate change include variable growth, which provides benefits from an extended growing season if temperatures increase (Cochrane et al. 2009), and non-specialised dietary and habitat preferences (Rijnsdorp et al. 2009).

The impact of climate change on a fishery will depend on the response of a species and its supporting ecosystem, the management structure of the fishery and capacity for change in human behaviour. Management strategies of the barramundi fishery of the Fitzroy River region exemplify the qualities that are likely to make a fishery stock more resilient to the impacts of climate change, at least in the medium term (i.e. next 50 years). These include the following: (1) a conservative harvest rate (King and MacFarlane 2006) achieved by limited-entry commercial fishing, spatial closures near sites of non-spawning aggregation, e.g. downstream of dams and weirs, and minimum and maximum size limits; (2) protection of the spawning stock (i.e. a maximum size limit to conserve large highly fecund females and an annual spawning closure); and (3) harvesting across many age classes, i.e. 2-32 years (Staunton-Smith et al. 2004). Managers of other fisheries within Australia and worldwide may need to consider using some of these strategies (if not already enacted) to enhance the resilience of fish stocks to climate change.

The challenge for managers of barramundi fisheries (or species with similar traits) will be to distinguish among variations in fishery-performance measures (e.g. annual catch) that are a consequence of regional inter-year climate variability from those that are a consequence of long-term, global climate 

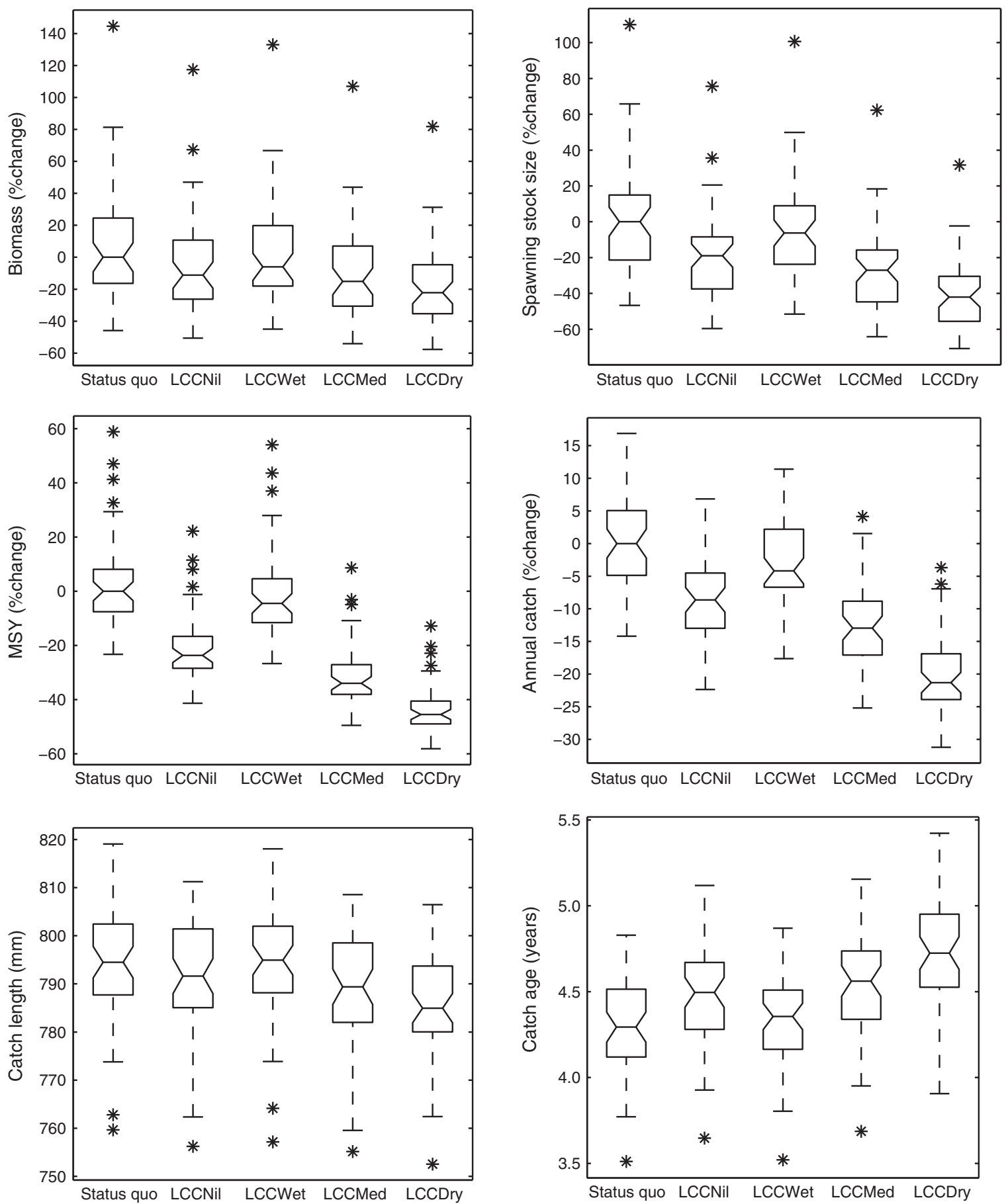

Flow scenario

Fig. 3. Box and whisker plots of mean fishery indicators over the last 20 years of each model simulation for $h=0.7$ under alternate flow scenarios, where status quo $=$ historic observed discharge to the estuary, LCCNil $=$ hypothetical latent + no climate change, LCCWet $=$ hypothetical latent + climate change wet, LCCMed = hypothetical latent + climate change median and LCCDry = hypothetical latent + climate change dry. Values are presented as percentage change relative to the status quo scenario. The boxes represent the 25th, median and 75th percentiles. The error bars indicate 1.5 times the inter-quartile range, and asterisk represents outlier values $(n=50)$.

change. In Queensland, commercial landings are reported and the age structures of key regional populations are monitored annually. These data provide real-time indices of trends in CPUE and year-class strength and can alert fishery managers to periods of stock decline. This information could identify the need for management intervention so that fishing pressures do not amplify climate-induced changes (Möllmann et al. 2008). 

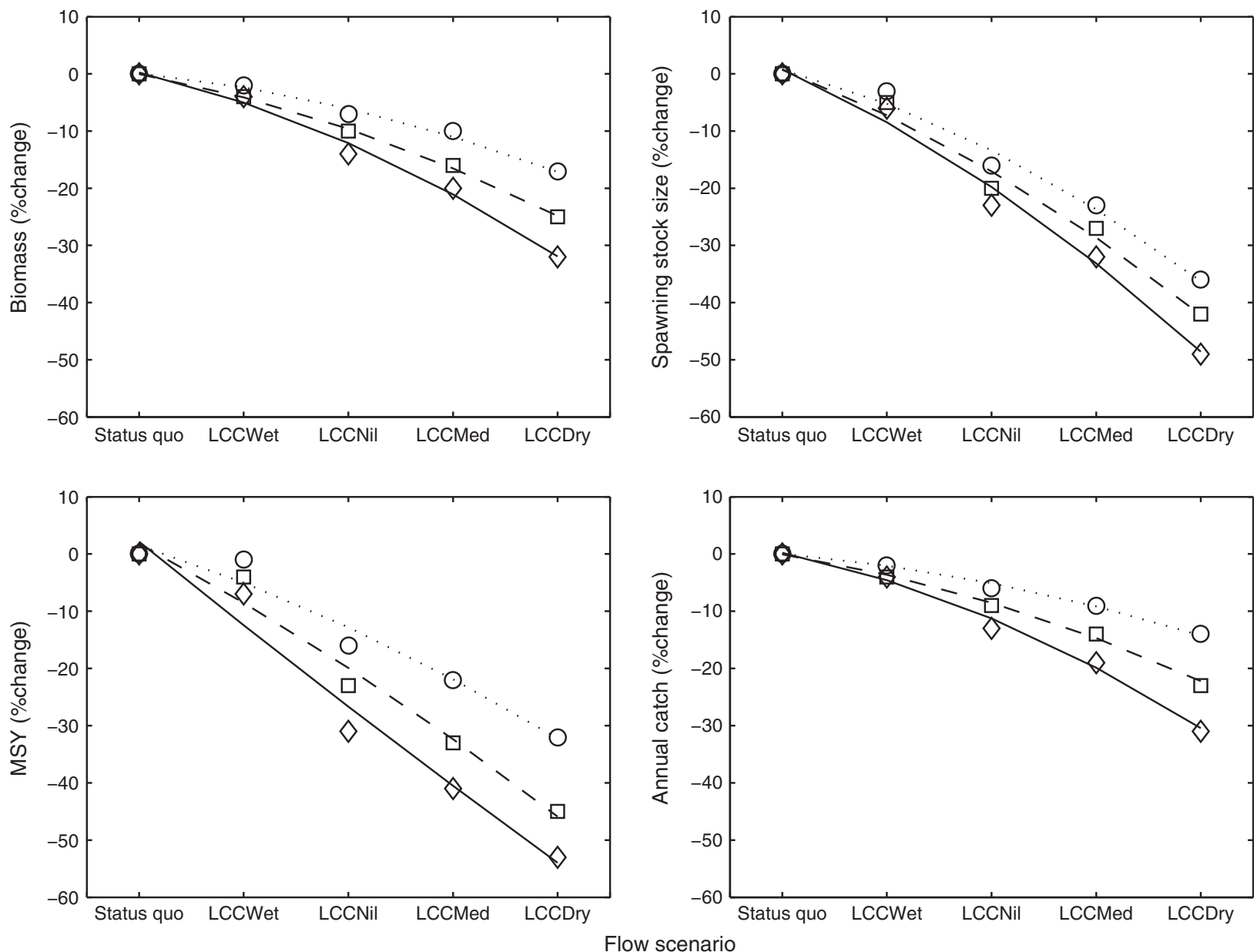

Fig. 4. Mean values of fishery indicators from model simulations of barramundi under alternate river-discharge scenarios and recruitment-curve steepness $(h)$, where status quo $=$ historic observed, $\mathrm{LCCNil}=$ hypothetical latent + no climate change, $\mathrm{LCCWet}=$ hypothetical latent + climate change wet, $\mathrm{LCCMed}=$ hypothetical latent + climate change median and LCCDry $=$ hypothetical latent + climate change dry. Values are presented as percentage change relative to the status quo scenario. $h=0.5(\diamond), h=0.7(\square)$ and $h=0.9(\bigcirc)$.

\section{International significance of findings}

Numerous species worldwide show life-history relationships with river discharge (Drinkwater and Frank 1994; Gillanders and Kingsford 2002; Gillson 2011) and are consequently vulnerable to changes in river discharge that occur from human development and climate change. Stocks of other tropical estuarine opportunists and species tolerant of or dependent on lowered estuarine salinities are likely to be similarly affected by climate change, including species such as banana prawns (Pennaeus merguiensis) (Vance et al. 1998), school prawns (Metapenaeus macleayi) (Ives et al. 2009), common snook, Atlantic white shrimp (Litopenaeus setiferus) and blue shrimp (Litopenaeus stylirostris) (Galindo-Bect et al. 2000). Our ability to simulate the fishery dynamics of a species under climate change was dependent on understanding the biological mechanisms that drive a population at regional scales (Kell et al. 2005). This reinforced the need for the collection of long-term environmental and ecological data, because most of this data cannot be collected retrospectively (Clark 2006).
Humans already affect the productivity of estuarine fisheries through the upstream abstraction of water and this is likely to happen more frequently in both time and space in the future (Vörösmarty et al. 2000). The current study suggested that the potential impacts of total abstraction of all licenced water (i.e. the activation of latent effort in water abstraction) were of the same order of magnitude as were the impacts of median climate change. These results are similar to those of Peterson and Kwak (1999), who found that long-term land-use changes such as the drainage of wetlands and channelisation of rivers modifies the storage capacity, infiltration and runoff characteristics of a catchment. The consequence is altered discharge regimes that they suggest are of greater detriment to riverine fishes (e.g. smallmouth bass, Micropterus dolomieu) than are the negative effects of increased temperature and river discharge projected to occur with global climate change.

Estuaries and their associated fish populations require freshwater to function. The results of the current study highlighted that managers of natural resources should be as concerned about 
the downstream effects of water abstraction as they are about long-term climate change. The extraction of water for human use and long-term changes in climate that result in reduced river discharges may undermine the inherent resilience of estuarine ecosystems and their dependent fisheries.

\section{Acknowledgements}

This work was funded by Agri-Science Queensland (Department of Agriculture, Fisheries and Forestry), in collaboration with the eWater Co-operative Research Centre. We thank Cia Musgrave (Department of Environment and Resource Management) for the provision of riverdischarge data under projected climate change and Bill Sawynok (Suntag, Australian National Sport Fishing Association) for access to the barramundi tag-recapture data. Warwick Nash and Thor Saunders made constructive comments on earlier versions of this paper. We thank the journal reviewers for their valuable comments which ultimately improved the manuscript.

\section{References}

Balston, J. (2009). An analysis of the impacts of long-term climate variability on the commercial barramundi (Lates calcarifer) fishery of north-east Queensland, Australia. Fisheries Research 99, 83-89. doi:10.1016/J.FISHRES.2009.05.001

Brander, K. (2010). Impacts of climate change on fisheries. Journal of Marine Systems 79, 389-402. doi:10.1016/J.JMARSYS.2008.12.015

Brown, C. J., Fulton, E. A., Hobday, A. J., Matear, R. J., Possingham, H. P., Bulman, C., Christensen, V., Forrest, R. E., Gehrke, P. C., Gribble, N. A., Griffiths, S. P., Lozano-Montes, H., Martin, J. M., Metcalf, S., Okey, T. A., Watson, R., and Richardson, A. J. (2010). Effects of climatedriven primary production change on marine food webs: implications for fisheries and conservation. Global Change Biology 16, 1194-1212. doi:10.1111/J.1365-2486.2009.02046.X

Cai, W., Crimp, S., Jones, R. N., Mclinnes, K., Durack, P., Cechet, B., Bathols, J., and Wilkinson, S. (2005). 'Climate Change in Queensland Under Enhanced Greenhouse Conditions.' (CSIRO Marine and Atmospheric Research: Melbourne.) Available at http:// www.longpaddock.qld.gov.au/about/publications/pdf/climatechange/ qldunderenhancedgreenhouse2004-2005/FullReport_HighQuality.pdf [accessed October 2011].

Caputi, N., Melville-Smith, R., de Lestang, P., Pearce, A., and Feng, M. (2010). The effect of climate change on the western rock lobster (Panulirus cygnus) fishery of Western Australia. Canadian Journal of Fisheries and Aquatic Sciences 67, 85-96. doi:10.1139/F09-167

Chiew, F. H. S., Piechota, T. C., Dracup, J. A., and McMahon, T. A. (1998). El Nino/Southern Oscillation and Australian rainfall, streamflow and drought: links and potential for forecasting. Journal of Hydrology 204, 138-149. doi:10.1016/S0022-1694(97)00121-2

Clark, B. M. (2006). Climate change: a looming challenge for fisheries management in southern Africa. Marine Policy 30, 84-95. doi:10.1016/ J.MARPOL.2005.06.006

Clark, R. A., Fox, C. J., Viner, D., and Livermore, M. (2003). North Sea cod and climate change-modelling the effects of temperature on population dynamics. Global Change Biology 9, 1669-1680. doi:10.1046/J.13652486.2003.00685.X

Cochrane, K., De Young, C., Soto, D., and Bahri, T. (2009). Climate change implications for fisheries and aquaculture: overview of current scientific knowledge. FAO Fisheries and Aquaculture Technical Paper No. 530. (FAO: Rome.) Available at http://www.fao.org/docrep/012/i0994e/ i0994e00.htm [accessed October 2011].

Drinkwater, K. F., and Frank, K. T. (1994). Effects of river regulation and diversion on marine fish and invertebrates. Aquatic Conservation: Freshwater and Marine Ecosystems 4, 135-151. doi:10.1002/AQC. 3270040205
Dunstan, D. J. (1959). The barramundi, Lates calcarifer (Bloch) in Queensland waters. Division of Fisheries and Oceanography Technical Paper, No. 5. CSIRO, Melbourne.

Fishbase (2009). Fishbase. Available at http://www.fishbase.org [accessed October 2011].

Ford, P., Tillman, P., Robson, B., and Webster, I. T. (2005). Organic carbon deliveries and their flow related dynamics in the Fitzroy Estuary. Marine Pollution Bulletin 51, 119-127. doi:10.1016/J.MARPOLBUL. 2004.10.019

Francis, R. I. C. C. (2011). Data weighting in statistical fisheries stock assessment models. Canadian Journal of Fisheries and Aquatic Sciences 68, 1124-1138. doi:10.1139/F2011-025

Galindo-Bect, M. S., Glenn, E. P., Page, H. M., Fitzsimmons, K., GalindoBect, L. A., Hernandez-Ayon, J. M., Petty, R. L., Garcia-Hernandez, J., and Moore, D. (2000). Penaeid shrimp landings in the upper Gulf of California in relation to Colorado River freshwater discharge. Fishery Bulletin 98, 222-225.

Gelman, A., Carlin, J. B., Stern, H. S., and Rubin, D. B. (2004). 'Bayesian Data Analysis.' 2nd edn. (Chapman \& Hall/CRC Press: New York.)

Genstat, R. E. M. L. (2008). 'Genstat for Windows, Release 11.1.' 11th edn. (VSN International Ltd: Oxford, UK.)

Geweke, J. D. (1992). Evaluating the accuracy of sampling-based approaches to calculating posterior moments. In 'Bayesian Statistics 4'. (Eds J. M. Bernado, J. O. Berger, A. P. Dawid and A. F. M. Smith.) pp. 169-194. (Clarendon Press: Oxford, UK.)

Gillanders, B. M., and Kingsford, M. J. (2002). Impact of changes in flow of freshwater on estuarine and open coastal habitats and the associated organisms. Oceanography and Marine Biology: An Annual Review 40, 233-309.

Gillanders, B. M., Elsdon, T. S., Halliday, I. A., Jenkins, G. P., Robins, J. B., and Valesini, F. J. (2011). Potential effects of climate change on Australian estuaries and fish utilising estuaries: a review. Marine and Freshwater Research 62, 1115-1131. doi:10.1071/MF11047

Gillson, J. (2011). Freshwater flow and fisheries production in estuarine and coastal systems: where a drop of rain is not lost. Reviews in Fisheries Science 19, 168-186. doi:10.1080/10641262.2011.560690

Grace, B., Handley, A., and Bajhau, H. (2008). Managing, monitoring, maintaining and modelling barramundi. Proceedings of the National Barramundi Workshop, 6-8 July 2005, Darwin, Northern Territory, and overview of the barramundi modelling workshop, 27 February - 3 March 2006. Perth, Western Australia. (Northern Territory Government: Darwin.) Available at http://www.nt.gov.au/d/Content/File/p/Fish_ Rep/FR90.pdf [accessed October 2011].

Gräwe, U., Wolff, J.-O., and Ribbe, J. (2010). Impact of climate variability on an east Australian bay. Estuarine, Coastal and Shelf Science 86, 247-257. doi:10.1016/J.ECSS.2009.11.020

Greenwood, P. H. (1976). 'A Review of the Family Centropomidae (Pisces, Perciformes).' (British Museum of Natural History: London.)

Griffin, R. K. (1987). Barramundi (Lates calcarifer) research in the Northern Territory, Australia. In 'Management of Wild and Cultured Sea Bass/ Barramundi (Lates calcarifer)'. (Eds J. W. Copland and D. L. Grey.) pp. 87-91. (Australian Centre for International Agricultural Research: Canberra.)

Haddon, M. (2001). 'Modelling and Quantitative Methods in Fisheries.' (Chapman \& Hall/CRC: New York.)

Hall, N. G., and Watson, R. A. (2000). A spatial representation of the tiger prawn (Penaeus esculentus) fishery in Shark Bay, Western Australia. In 'Fish Movement and Migration'. (Eds D. A. Hancock, D. C. Smith and J. D. Koehn.) pp. 212-230. (Australian Society for Fish Biology: Albury, Vic.)

Halliday, I. A., Robins, J. B., Mayer, D. G., Staunton Smith, J., and Sellin, M. J. (2011). Freshwater flows affect the year-class strength of barramundi Lates calcarifer in the Fitzroy River estuary, central Queensland. Proceedings of the Royal Society of Queensland 116, 1-11. 
Harley, C. D. G., Hughes, A. R., Hultgren, K. M., Miner, B. G., Sorte, C. J. B., Thornber, C. S., Rodriguez, L. F., Tomanek, L., and Williams, S. L. (2006). The impacts of climate change in coastal marine systems. Ecology Letters 9, 228-241. doi:10.1111/J.1461-0248.2005.00871.X

Hilborn, R., and Stokes, K. (2011). Defining overfished stocks: have we lost the plot? Fisheries (Bethesda, Md.) 35, 113-120. doi:10.1577/15488446-35.3.113

Hobday, A. J., Poloczanska, E. S., and Matear, R. J. (2008). Implications of Climate Change for Australian Fisheries and Aquaculture: a preliminary assessment. Report to the Department of Climate Change, Canberra Available at http://www.climatechange.gov.au/publications/fisheries/ fisheries.aspx [accessed October 2011].

Howard, W. R., Havenhand, J., Parker, L., Raftos, D., Ross, P., Williamson, J., and Matear, R. (2009). Ocean acidification. In 'A Marine Climate Change Impacts and Adaptation Report Card for Australia 2009'. (Eds E. S. Poloczanska, A. J. Hobday and A. J. Richardson.) NCCARF Publication 05/09. Available at http://www.oceanclimatechange org.au/content/index.php/site/report_card_extended/category/ocean_ acidification [accessed October 2011].

IPCC (2007). Climate change 2007: synthesis report of the 4th IPCC assessment. Intergovernmental Panel on Climate Change, Geneva.

Ives, M. C., Scandol, J. P., Montgomery, S. S., and Suthers, I. M. (2009). Modelling the possible effects of climate change on an Australian multifleet prawn fishery. Marine and Freshwater Research 60, 1211-1222.

Jobling, J. (1997). Temperature and growth: modulation of growth rate via temperature change. In 'Global Warming: Implications for Freshwater and Marine Fish'. (Eds C. M. Wood and D. G. McDonald.) pp. 225-254. (Cambridge University Press: Cambridge, UK.)

Katersky, R. S., and Carter, C. G. (2007). A preliminary study on growth and protein synthesis of juvenile barramundi, Lates calcarifer at different temperatures. Aquaculture 267, 157-164. doi:10.1016/J.AQUACUL TURE.2007.02.043

Kell, L. T., Pilling, G. M., and O'Brien, C. M. (2005). Implications of climate change for the management of North Sea cod (Gadus morhua). ICES Journal of Marine Science 62, 1483-1491. doi:10.1016/ J.ICESJMS.2005.05.006

Kennedy, V. (1990). Anticipated effects of climate change on estuarine and coastal fisheries. Fisheries 15, 16-24. doi:10.1577/1548-8446(1990) $015<0016$ :AEOCCO $>2.0 . \mathrm{CO} ; 2$

Keyl, F., and Wolff, M. (2008). Environmental variability and fisheries: what can models do? Reviews in Fish Biology and Fisheries 18, 273-299. doi:10.1007/S11160-007-9075-5

King, J. R., and MacFarlane, G. A. (2006). A framework for incorporating climate regime shifts into the management of marine resources. Fisheries Management and Ecology 13, 93-102. doi:10.1111/J.1365-2400. 2006.00480.X

Koehn, J. D., Hobday, A. J., Pratchett, M. S., and Gillanders, B. M. (2011). Climate change and Australian marine and freshwater environments, fishes and fisheries: synthesis and options for adaptation. Marine and Freshwater Research 62, 1-17.

Leigh, G. M., Williams, A. J., Begg, G. A., Gribble, N. A., and Whybird, O. J. (2006). Stock assessment report on Queensland East Coast red throat emperor fishery - 2006. Department of Primary Industries and Fisheries, Queensland: Brisbane. Available at http://www.dpi.qld.gov.au/ 28_11074.htm [acessed October 2011].

Lough, J. M. (2009). Temperature. In 'A Marine Climate Change Impacts and Adaptation Report Card for Australia 2009'. (Eds E. S. Poloczanska, A. J. Hobday and A. J. Richardson.) NCCARF Publication 05/09. Available at http://www.oceanclimatechange.org.au/content/index. php/site/report_card_extended_2/category/temperature [accessed October 2011].

Lough, J. M., and Hobday, A. J. (2011). Observed climate change in Australian marine and freshwater environments. Marine and Freshwater Research 62, 984-999. doi:10.1071/MF10272
Milton, D., Halliday, I., Sellin, M., Marsh, R., Staunton-Smith, J., and Woodhead, J. (2008). The effect of habitat and environmental history on otolith chemistry of barramundi Lates calcarifer in estuarine populations of a regulated tropical river. Estuarine, Coastal and Shelf Science 78, 301-315. doi:10.1016/J.ECSS.2007.12.009

Möllmann, C., Muller-Karulis, B., Kornilovs, G., and St John, M. A. (2008). Effects of climate and overfishing on zooplankton dynamics and ecosystem structure: regime shifts, trophic cascade, and feedback loops in a simple ecosystem. ICES Journal of Marine Science 65, 302-310. doi:10.1093/ICESJMS/FSM197

Muller, R. G., and Taylor, R. G. (2006). The 2005 stock assessment update of common snook, Centropomus undecimalis. Florida Fish and Wildlife Conservation Commission. Available at http://myfwc.com/media/ 203323/snook_assessment_2005_5505.pdf [accessed October 2011].

Ottersen, G., Kim, S., Huse, G., Polovina, J. J., and Stenseth, N. C. (2010). Major pathways by which climate may force marine fish populations. Journal of Marine Systems 79, 343-360. doi:10.1016/J.JMARSYS 2008.12.013

Pankhurst, N. W., and Munday, P. L. (2011). Effects of climate change on fish reproduction and early life history stages. Marine and Freshwater Research 62, 1015-1026. doi:10.1071/MF10269

Pender, P. J., and Griffin, R. K. (1996). Habitat history of barramundi Lates calcarifer in a north Australian river system based on barium and strontium levels in scales. Transactions of the American Fisheries Society 125, 679-689. doi:10.1577/1548-8659(1996)125<0679: HHOBCI $>2.3 . \mathrm{CO} ; 2$

Peterson, J. T., and Kwak, T. J. (1999). Modeling the effects of land use and climate change on riverine smallmouth bass. Ecological Applications 9, 1391-1404. doi:10.1890/1051-0761(1999)009[1391:MTEOLU] 2.0.CO; 2

Pittock, J., Hansen, L. J., and Abell, R. (2008). Running dry: freshwater biodiversity, protected areas and climate change. Biodiversity 9, 30-38. doi:10.1080/14888386.2008.9712905

Plagányi, É. E., Bell, J. D., Bustamante, R. H., Dambacher, J. M., Dennis, D M., Dichmont, C. M., Dutra, L. X. C., Fulton, E. A., Hobday, A. J., Ingrid van Putten, E., Smith, F., Smith, A. D. M., and Zhou, S. (2011) Modelling climate-change effects on Australian and Pacific aquatic ecosystems: a review of analytical tools and management implications. Marine and Freshwater Research 62, 1132-1147. doi:10.1071/ MF10279

Poloczanska, E. S., Babcock, R., Butler, A., Hobday, A., Hoegh-Guldberg, O., Kunz, T., Matear, R., Milton, D., Okey, T., and Richardson, A. (2007). Climate change and Australian marine life. Oceanography and Marine Biology: an Annual Review 45, 407-478.

Punt, A. E., Hobday, D. K., and Flint, R. (2006). Bayesian hierarchicial modelling of maturity-at-length for rock lobster, Janus edwardsii, off Victoria, Australia. Marine and Freshwater Research 57, 503-511. doi:10.1071/MF05261

Queensland Centre for Climate Change Excellence (QCCCE) (2009). 'Climate Change in the Central Queensland Region.' (Queensland Centre for Climate Change Excellence, Queensland Government: Brisbane.) Available at http://www.climatechange.qld.gov.au/pfd/ regionsummary-cq.pdf [accessed October 2011].

Rajaguru, S. (2002). Critical thermal maximum of seven estuarine fishes. Journal of Thermal Biology 27, 125-128. doi:10.1016/S0306-4565(01) 00026-2

Ridgway, K., and Hill, K. (2009). The East Australian Current. In 'A Marine Climate Change Impacts and Adaptation Report Card for Australia 2009'. (Eds E. S. Poloczanska, A. J. Hobday and A. J. Richardson.) NCCARF Publication 05/09. http://www.oceanclimatechange.org.au/ content/index.php/site/report_card_extended_2/category/east_australian_ current [accessed October 2011].

Rijnsdorp, A. D., Peck, M. A., Engelhard, G. H., Möllmann, C., and Pinnegar, J. K. (2009). Resolving the effect of climate change on fish 
populations. ICES Journal of Marine Science 66, 1570-1583. doi:10.1093/ICESJMS/FSP056

Robins, J. B., Halliday, I. A., Staunton-Smith, J., Mayer, D. G., and Sellin, M. J. (2005). Freshwater-flow requirements of estuarine fisheries in tropical Australia: a review of the state of knowledge and application of a suggested approach. Marine and Freshwater Research 56, 343-360. doi:10.1071/MF04087

Robins, J., Mayer, D., Staunton-Smith, J., Halliday, I., Sawynok, B., and Sellin, M. (2006). Variable growth rates of the tropical estuarine fish barramundi Lates calcarifer (Bloch) under different freshwater flow conditions. Journal of Fish Biology 69, 379-391. doi:10.1111/J.10958649.2006.01100.X

Russell, D. J., and Garrett, R. N. (1985). Early life history of barramundi, Lates calcarifer (Bloch), in north-eastern Queensland. Australian Journal of Marine and Freshwater Research 36, 191-201. doi:10.1071/ MF9850191

Staunton-Smith, J., Robins, J. B., Mayer, D. G., Sellin, M. J., and Halliday, I. A. (2004). Does the quantity and timing of fresh water flowing into a dry tropical estuary affect year-class strength of barramundi (Lates calcarifer)? Marine and Freshwater Research 55, 787-797. doi:10.1071/MF03198

Vance, D. J., Haywood, M. D. E., Heales, D. S., Kenyon, R. A., and Loneragan, N. R. (1998). Seasonal and annual variation in abundance of postlarval and juvenile banana prawns Penaeus merguiensis and environmental variation in two estuaries in tropical northeastern Australia: a six year study. Marine Ecology Progress Series 163, 21-36. doi:10.3354/MEPS163021

Vörösmarty, C. J., Green, P., Salisbury, J., and Lammers, R. B. (2000). Global water resources: vulnerability from climate change and population growth. Science 289, 284-288. doi:10.1126/SCIENCE.289. 5477.284

Water Assessment Group (2009). Preparation of climate change data for the Fitzroy River Basin water supply scheme. State of Queensland, Department of Environment and Water Resource Management, Brisbane. 